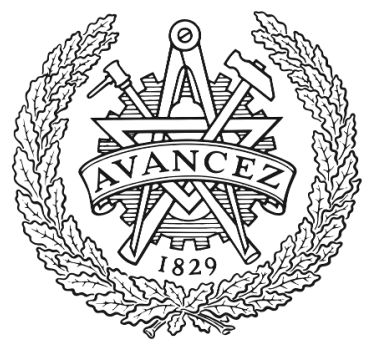

CHALMERS

UNIVERSITY OF TECHNOLOGY

\title{
Thermally Activated in Situ Doping Enables Solid-State Processing of Conducting Polymers
}

Downloaded from: https://research.chalmers.se, 2023-04-26 04:43 UTC

Citation for the original published paper (version of record):

Kroon, R., Hofmann, A., Yu, L. et al (2019). Thermally Activated in Situ Doping Enables Solid-State Processing of Conducting Polymers. Chemistry of Materials, 31(8): 2770-2777.

http://dx.doi.org/10.1021/acs.chemmater.8b04895

N.B. When citing this work, cite the original published paper. 


\title{
Thermally Activated in Situ Doping Enables Solid-State Processing of Conducting Polymers
}

\author{
Renee Kroon, ${ }^{* \dagger \odot}$ Anna I. Hofmann, ${ }^{\dagger}{ }^{\oplus}$ Liyang Yu, ${ }^{\circledR}$ Anja Lund, and Christian Müller*(i) \\ Department of Chemistry and Chemical Engineering, Chalmers University of Technology, 41296 Göteborg, Sweden
}

Supporting Information

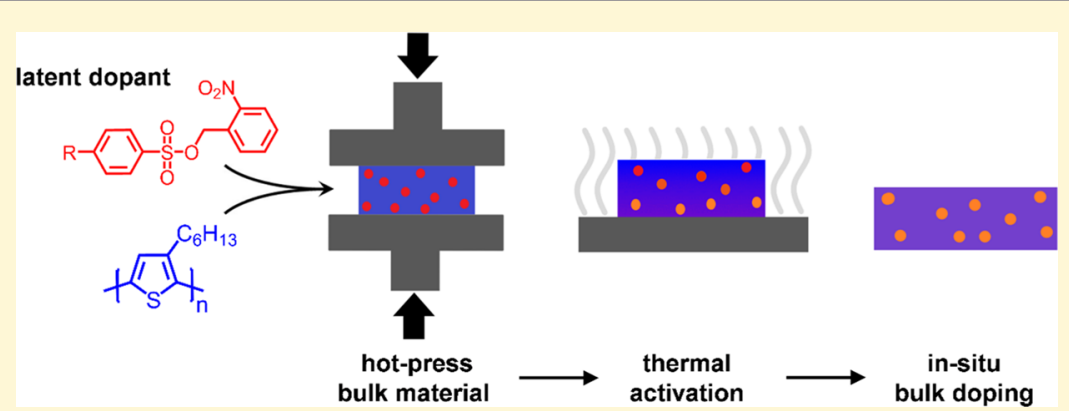

ABSTRACT: Free-standing bulk structures encompassing highly doped conjugated polymers are currently heavily explored for wearable electronics as thermoelectric elements, conducting fibers, and a plethora of sensory devices. One-step manufacturing of such bulk structures is challenging because the interaction of dopants with conjugated polymers results in poor solution and solid-state processability, whereas doping of thick conjugated polymer structures after processing suffers from diffusion-limited transport of the dopant. Here, we introduce the concept of thermally activated latent dopants for in situ bulk doping of conjugated polymers. Latent dopants allow for noninteractive coprocessing of dopants and polymers, while thermal activation eliminates any thickness-dependent diffusion and activation limitations. Two latent acid dopants were synthesized in the form of thermal acid generators based on aryl sulfonic acids and an $o$-nitrobenzyl capping moiety. First, we show that these acid dopant precursors can be coprocessed noninteractively with three different polythiophenes. Second, the polymer films were doped in situ through thermal activation of the dopants. Ultimately, we demonstrate that solid-state processing with a latent acid dopant can be readily carried out and that it is possible to dope more than $100 \mu \mathrm{m}$-thick polymer films through thermal activation of the latent dopant.

\section{INTRODUCTION}

Additives such as fillers, plasticizers, and stabilizers are commonly used to enhance the mechanical properties, processability, and environmental stability of commodity polymers. Similarly, redox-active additives called dopants are widely employed to introduce charge carriers in conjugated polymers, in order to boost their electronic performance in thin-film electronic devices such as field-effect transistors, ${ }^{1}$ organic solar cells, ${ }^{2}$ and light-emitting diodes. ${ }^{3}$ Further, freestanding bulk structures comprising highly doped conjugated polymers attract attention as thermoelectric elements, ${ }^{4,5}$ conducting fibers for electronic textiles, ${ }^{6-8}$ stretchable sensors, ${ }^{9}$ and electrodes for electronic skin and muscles. ${ }^{10,11}$

One-step processing of doped conjugated polymers is difficult to carry out because of their poor solubility and absence of an accessible melt phase. In solution, for example, conjugated polymers tend to form intractable complexes with dopants, leading to inhomogeneous films upon drying. ${ }^{12-14}$ One route to enhance processability is through selection of suitable counterions, for example, dodecylbenzene sulfonic acid (DBSA) or poly(styrenesulfonate), which enhance solubility in organic solvents or water, respectively, and facilitate melt processing upon blending with commodity polymers. $^{15}$ Sequential processing has emerged as an alternative where a conjugated polymer is first processed from a solution or a melt, followed by introduction of the dopant via an orthogonal solvent ${ }^{12,13,16,17}$ or via the vapor phase. ${ }^{18-21}$ However, such a two-step process is challenging in the case of thick conjugated polymer structures, as it involves very long doping times because of diffusion-limited transport of the dopant. ${ }^{22}$ Thus, it would be highly desirable to develop means that permit coprocessing of polymers and dopants into thick structures, while avoiding the premature formation of intractable polymer/dopant complexes.

One strategy that has been explored to coprocess conjugated polymers and dopants noninteractively involves the use of photoacid generators (PAGs), a class of compounds that offer latent acid functionality instead of acting as an active acid dopant. In this way, a semiconducting polymer can be easily coprocessed with an acid dopant precursor, after which the active acid dopant can be accessed through irradiation with (most commonly) ultraviolet (UV) light. Within the field of

Received: November 23, 2018

Revised: $\quad$ March 7, 2019

Published: April 2, 2019 
thin-film organic electronics, PAGs have predominantly been used to cross-link functionalized conjugated polymers to obtain enhanced structural stability in organic light-emitting diodes $^{23-25}$ and organic solar cells ${ }^{26}$ but also for patterning of conjugated polymers. ${ }^{27-36}$ Several studies have demonstrated the use of PAGs for direct photopatterning of thin films of conjugated polymers, thereby utilizing the intractability of the doped conjugated polymer/counterion complex. ${ }^{37-40} \mathrm{Re}-$ cently, a dimer dopant precursor has been developed that, upon photoactivation, resulted in the formation of two active n-type dopant molecules. ${ }^{41}$

However, the use of PAGs to dope millimeter-thick structures is not feasible, as UV light would only reach a micrometer-thin surface layer. Heat has been used as a stimulus to immobilize thin-film structures of conjugated polymers by thermal cleavage of solubilizing side chains or thermally activated cross-linking. ${ }^{42-47}$ Using heat to trigger a doping event post-processing would eliminate thicknessdependent diffusion and activation limitations. Fortunately, some acid precursors can also be activated via heatcommonly referred to as thermal acid generators (TAGs) which are primarily used as curing agents for coatings. ${ }^{48,49}$ In 1991, Angelopoulos et al. considered in situ doping of thin spin-coated polyaniline films with diethylammonium triflate salt through thermal activation and then went on to use these latent dopants for lithography through activation via e-beam irradiation. $^{50}$ We argue that the use of TAGs as dopant precursors is an intriguing route for coprocessing of conjugated polymers and dopants, which would considerably simplify manufacturing of thick conducting polymer structures.

In this work, we introduce the use of TAGs as latent dopants, which can be coprocessed with a variety of polythiophenes such as poly(3-hexylthiophene) (P3HT), poly [2,5-bis (3-hexyldecylthiophen-2-yl)thieno[3,2-b]thiophene] (C16-PBTTT), and a glycolated polythiophene derivative $\mathrm{p}\left(\mathrm{g}_{4} 2 \mathrm{~T}-\mathrm{T}\right)$. In a second step, in situ bulk doping can be carried out on demand through thermal activation. In addition, we demonstrate that solid-state processing and subsequent thermally induced doping of thick P3HT structures can be readily carried out.

\section{RESULTS AND DISCUSSION}

Acid doping of conjugated polymers occurs through protonation of the conjugated polymer, thereby removing electrons from the conjugated backbone and resulting in a pdoped material with the conjugate base acting as the counterion. We chose to work with two sulfonic acids, ethylbenzene sulfonic acid (EBSA) and DBSA, which are widely explored acid dopants for organic semiconductors. $15,17,51,52$ As the capping moiety for the sulfonic acids, we selected the photocleavable group 2-nitrobenzyl alcohol. The 2-nitrobenzyl moiety is easily installed and has been comprehensively studied as a photocleavable protecting group, ${ }^{53}$ and thermal decapping occurs autonomously via intramolecular displacement. ${ }^{54}$ The intramolecular displacement involves an oxygen transfer reaction from the $o$-nitro group onto the benzylic carbon that triggers the release of the arylsulfonic ester group. The resulting arylsulfonate subsequently abstracts a proton from the reaction intermediate to form the activated sulfonic acid that proceeds to dope the conjugated polymer. The 2-nitrosobenzaldehyde byproduct that is formed after rearrangement either persists in the polymer and potentially dimerizes to form azobenzene- 2,2 ' dicarboxylic acid or evaporates from the polymer matrix. ${ }^{55}$

To obtain the latent dopants, we first reacted the sulfonyl chloride derivative of EBSAand DBSA with 2-nitrobenzyl alcohol, offering the TAGs in moderate to high yields. The capped EBSA (EBSAc) was isolated as a cream-colored powder that could be purified to white crystals via recrystallization from methanol, whereas the capped DBSA (DBSAc) was purified through flash column chromatography (performed in the dark) to afford the target product as a slightly yellow oil. For both TAG dopants, ${ }^{1} \mathrm{H}$ - and ${ }^{13} \mathrm{C}$ NMR spectra were recorded to verify their chemical structure (Supporting Information Figures S1-S4).

We continued our studies by determining a suitable activation temperature for the TAGs with thermal gravimetric analysis (TGA) combined with differential scanning calorimetry (DSC) (Figure 1a). Supporting Information For DBSAc, we find an exothermic transition starting at $\sim 120{ }^{\circ} \mathrm{C}$, with a maximum at $\sim 140{ }^{\circ} \mathrm{C}$, which we attribute to the thermal decapping of the TAG. For EBSAc, we find that the thermal decapping is lowered by $\sim 10{ }^{\circ} \mathrm{C}$, corresponding to the onset
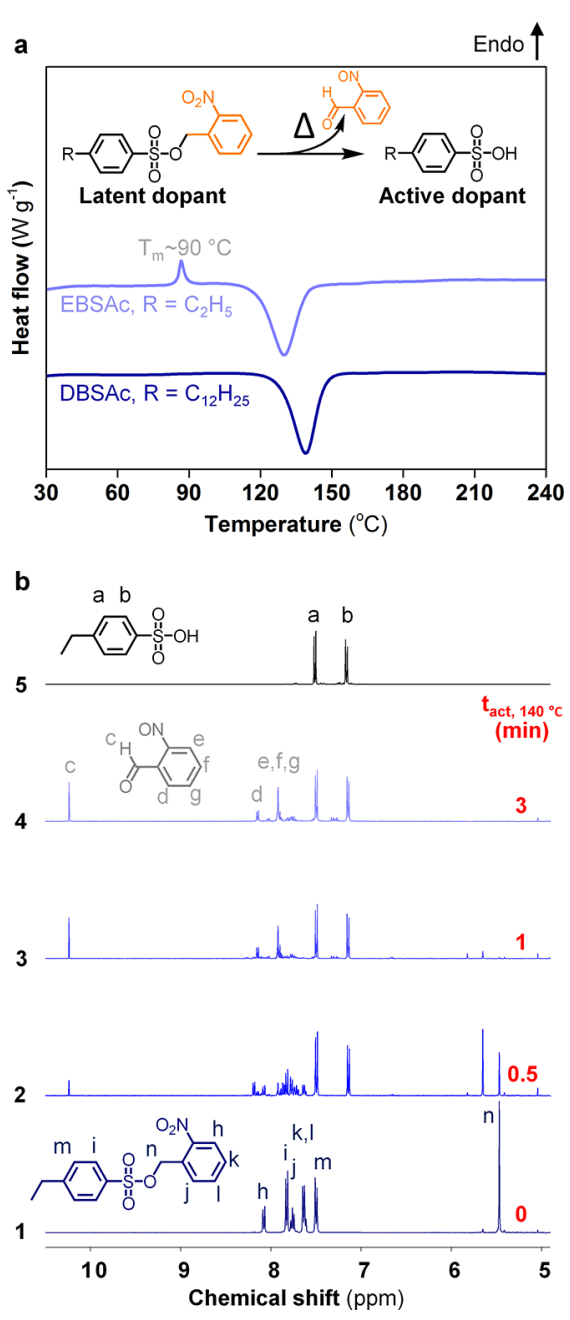

Figure 1. (a) Schematic of TAG dopant activation and corresponding DSC thermograms (first heating) for the EBSAc and DBSAc TAG dopants, (b) ${ }^{1} \mathrm{H}$ NMR spectra and peak assignment of EBSAc (spectrum 1), reference EBSA (spectrum 5), and the evolution of the ${ }^{1} \mathrm{H}$ NMR spectra upon thermal decapping of EBSAc at $140{ }^{\circ} \mathrm{C}$ for $t_{\text {act }}$ $=0.5,1$, and $3 \mathrm{~min}$ (spectra $2-4$ ). 

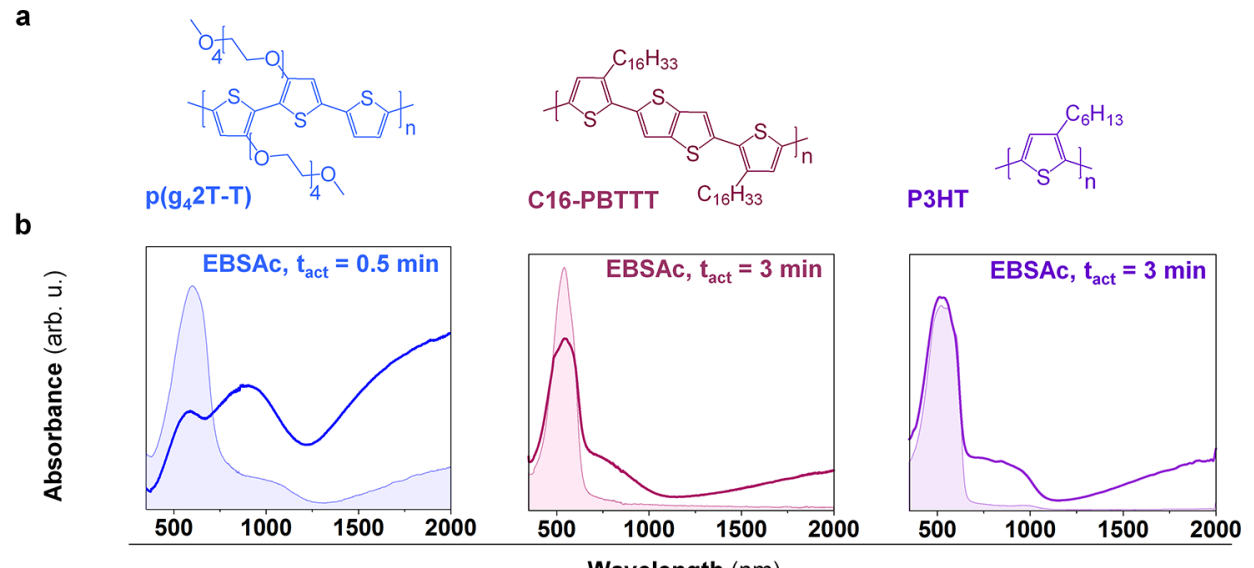

C

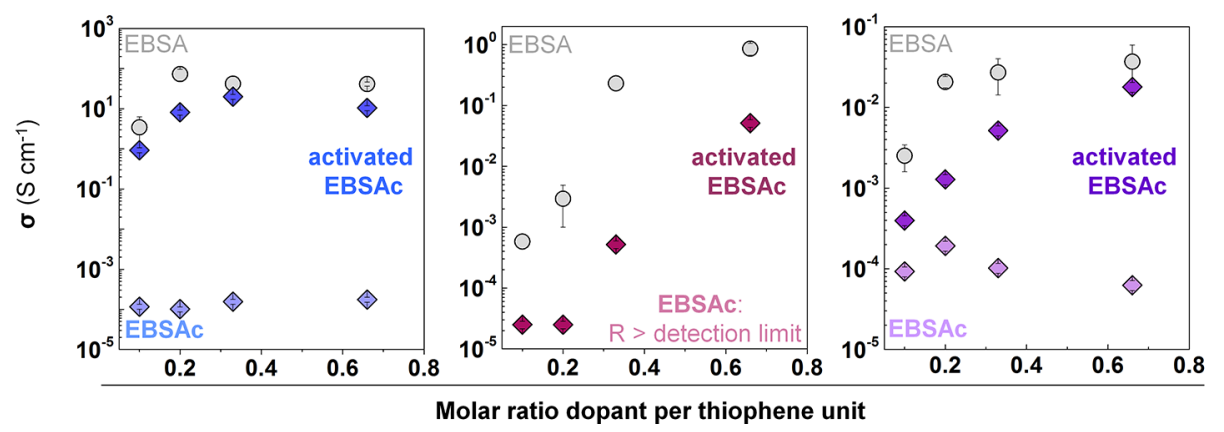

Figure 2. (a) Chemical structures of the conjugated polymers used in this study; (b) evolution of UV-vis-NIR spectra of $\mathrm{p}\left(\mathrm{g}_{4} 2 \mathrm{~T}-\mathrm{T}\right)$, C16PBTTT, and P3HT coprocessed with 0.66 molar ratio EBSAc as-cast (filled spectra) and after activation of the EBSAc dopant (open spectra), and (c) electrical conductivity of drop-cast $\mathrm{p}\left(\mathrm{g}_{4} 2 \mathrm{~T}-\mathrm{T}\right)$ (top), C16-PBTTT (middle), and P3HT (bottom) processed with varying amounts of EBSAc before (light-colored diamonds) and after (dark-colored diamonds) thermal activation of the dopant. Figure $2 \mathrm{~b}$ also shows the electrical conductivity of reference samples of each semiconductor polymer doped with different amounts of EBSA (gray circles).

and peak values of $\sim 110$ and $\sim 130{ }^{\circ} \mathrm{C}$, respectively. In addition, we observe an endothermic transition, which we attribute to melting of solid EBSAc, with a melting temperature $\left(T_{\mathrm{m}}\right) \sim 90{ }^{\circ} \mathrm{C}$. A minor reduction in mass is observed after thermal decapping, $\sim 3 \%$ at $150{ }^{\circ} \mathrm{C}$, after which the loss of mass accelerates (Supporting Information Figure S5). As we noticed a slight almond-like smell during decapping, we believe that the initial mass loss can be attributed to the evaporation of 2-nitrosobenzaldehyde, which is the byproduct after thermal activation of the TAG dopants. For consistency, we chose to use one activation temperature $\left(T_{\text {act }}\right)$ of $140{ }^{\circ} \mathrm{C}$ when using these TAG dopants, as both molecules readily decap at this temperature over a period of a few minutes.

We employed ${ }^{1} \mathrm{H}$ NMR to analyze the decapping efficiency of the TAG molecules in DMSO- $d_{6}$ (boiling point $=189^{\circ} \mathrm{C}$ ) that were exposed to $T_{\text {act }}=140{ }^{\circ} \mathrm{C}$ for progressively longer activation times (Figure 1b, Supporting Information Figure S6). We observed that both EBSAc and DBSAc are converted rapidly, judged by the disappearance of the aryl methylene peak at $5.47 \mathrm{ppm}$ and a concomitant appearance of a doublet at $7.14 \mathrm{ppm}$. Together with the doublet at $7.50 \mathrm{ppm}$, this peak corresponds to formation of the liberated acid, which is in excellent agreement with the ${ }^{1} \mathrm{H}$ NMR spectrum that we recorded for the pure acid. The concomitant appearance of a singlet at $\sim 10.2 \mathrm{ppm}$, doublet at $8.15 \mathrm{ppm}$, and an overlayed multiplet at $\sim 7.9 \mathrm{ppm}$ with an integral ratio of 1:1:3 suggests the formation of 2-nitrosobenzaldeyde, which is the main expected reaction byproduct. From the peak integrals at 7.50 and $7.14 \mathrm{ppm}$, we calculate that both TAG dopants were decapped for $\sim 70 \%$ after $30 \mathrm{~s}$ and that complete decapping was achieved after $\sim 1 \mathrm{~min}$ at $140{ }^{\circ} \mathrm{C}$. Thus, the ${ }^{1} \mathrm{H}$ NMR experiment shows that the TAGs have a similar activation time $\left(t_{\text {act }}\right) \approx 1$ min and can be converted quickly and completely at a $T_{\text {act }}$ of $140{ }^{\circ} \mathrm{C}$. In addition, we performed thermal stability studies using the free DBSA and EBSA acid dopants with the polythiophene $\mathrm{p}\left(\mathrm{g}_{4} 2 \mathrm{~T}-\mathrm{T}\right)$ (see Figure 2 for chemical structure) and measured the electrical conductivity of acid-doped $\mathrm{p}\left(\mathrm{g}_{4} 2 \mathrm{~T}-\mathrm{T}\right)$ to asses thermal degradation upon prolonged exposure to elevated temperatures (Supporting Information Figure S7). We have selected $\mathrm{p}\left(\mathrm{g}_{4} 2 \mathrm{~T}-\mathrm{T}\right)$ for this study, as we believe that its good compatibility with polar dopants ${ }^{52,56}$ makes it the most sensitive probe to study thermal degradation. The electrical conductivity $\left(\sigma_{0} \approx 50 \mathrm{~S} \mathrm{~cm}^{-1}\right)$ of both DBSA- and EBSA-doped $\mathrm{p}\left(\mathrm{g}_{4} 2 \mathrm{~T}-\mathrm{T}\right)$ remains constant for an annealing time of at least $30 \mathrm{~min}$ at an annealing temperature of $140{ }^{\circ} \mathrm{C}$, indicating that the thermal stability of acid-doped $\mathrm{p}\left(\mathrm{g}_{4} 2 \mathrm{~T}-\mathrm{T}\right)$ vastly exceeds the activation time of $t_{\text {act }}=1 \mathrm{~min}$ at $T_{\text {act }}=140{ }^{\circ} \mathrm{C}$.

To test the generality of the latent doping approach, we studied EBSAc in combination with $\mathrm{p}\left(\mathrm{g}_{4} 2 \mathrm{~T}-\mathrm{T}\right), \mathrm{P} 3 \mathrm{HT}$, and C16-PBTTT (see Figure 2a for chemical structures) as these polymers have successfully been p-type doped with acid dopants before. ${ }^{17,51,52,57,58} \mathrm{We}$ drop-cast chlorobenzene solutions of each polymer with different molar ratios (0.1, $0.2,0.33$, and 0.66 with regard to the average mass of one aromatic moiety) of the EBSAc dopant onto poly(ethylene terephthalate) substrates and collected absorption spectra of each polymer/TAG mixture before and after thermal activation (Figure 2b) with UV-vis-NIR spectroscopy. Before doping (filled spectra), the optical spectra show the absorption 
features of the parent polymer as well as a minor polaron peak. We explain the slight doping of each polymer with photochemical activation of the TAG dopant.

After activation of the EBSAc TAG dopant at $140{ }^{\circ} \mathrm{C}$, the absorption spectrum (solid lines) of $\mathrm{p}\left(\mathrm{g}_{4} 2 \mathrm{~T}-\mathrm{T}\right)$ markedly changes; its pristine absorption decreases while the polaron absorption ( $E_{\text {photon }}: 0.65-2 \mathrm{eV}$ ) strongly increases. The same effect is observed for P3HT and C16-PBTTT but is not as pronounced. An activation time of $t_{\text {act }}=0.5 \mathrm{~min}$ proved to be sufficient to highly dope $\mathrm{p}\left(\mathrm{g}_{4} 2 \mathrm{~T}-\mathrm{T}\right)$ with EBSAc, whereas P3HT and C16-PBTTT required longer activation times $\left(t_{\text {act }}=\right.$ $3 \mathrm{~min}$ ) to result in more pronounced levels of doping. We explain the difference in activation time between the aliphatic P3HT and C16-PBTTT, and the more polar $\mathrm{p}\left(\mathrm{g}_{4} 2 \mathrm{~T}-\mathrm{T}\right)$ by enhanced compatibility of the TAG-dopant with the latter. For the C16-PBTTT/EBSAc system, we found that a subsequent annealing step at $100{ }^{\circ} \mathrm{C}$ for 15 min resulted in a further increase of the polaron peak (Supporting Information Figure S8). ${ }^{59}$ Conversely, when we used DBSAc as the TAG dopant, an additional annealing step was not needed to reach similar doping levels (Supporting Information Figure S8).

We went on to measure the electrical conductivity of thicker drop-cast $(\sim 1-10 \mu \mathrm{m})$ polymer/EBSAc films, both before and after thermal activation as well as polymer/EBSA films for comparison (Figure 2c). Before thermal activation, all polymer/EBSAc films display low values of $\sigma \approx 10^{-4} \mathrm{~S} \mathrm{~cm}^{-1}$ for $\mathrm{p}\left(\mathrm{g}_{4} 2 \mathrm{~T}-\mathrm{T}\right) / \mathrm{EBSAc}$ and P3HT/EBSAc. We were unable to obtain a conductivity value for C16-PBTTT/EBSAc as the resistivity of the films exceeded the detection limit (500 M $\Omega$ ) of our measurement setups. After activating the TAG-dopant at $140{ }^{\circ} \mathrm{C}$, the electrical conductivity of each polymer increased by several orders of magnitude. For P3HT and C16-PBTTTbased films, the electrical conductivity increased progressively with larger amounts of the EBSAc dopant, achieving modest electrical conductivities for P3HT/EBSAc and C16-PBTTT/ EBSAc after activation of the TAG dopant $\left(t_{\text {act }}=3 \mathrm{~min}\right), 2 \times$ $10^{-2}$ and $5 \times 10^{-2} \mathrm{~S} \mathrm{~cm}^{-1}$, respectively. P3HT/EBSA reference films achieved a similar maximum $\sigma \approx 4 \times 10^{-2} \mathrm{~S} \mathrm{~cm}^{-1}$, whereas C16-PBTTT/EBSA reference films achieved higher $\sigma$ $\approx 1 \mathrm{~S} \mathrm{~cm}^{-1}$, for a 0.66 molar ratio EBSAc per thiophene unit. In contrast, $\mathrm{p}\left(\mathrm{g}_{4} 2 \mathrm{~T}-\mathrm{T}\right)$ achieved a much higher electrical conductivity of $\sim 22 \mathrm{~S} \mathrm{~cm}^{-1}$ after TAG dopant activation $\left(t_{\text {act }}=\right.$ $0.5 \mathrm{~min}$ ), which is, to the best of our knowledge, a record value regarding latent doping of semiconductor polymers. For $\mathrm{p}\left(\mathrm{g}_{4} 2 \mathrm{~T}-\mathrm{T}\right) /$ EBSA reference films, the electrical conductivity initially increased with EBSA concentration to $\sigma \approx 73 \mathrm{~S} \mathrm{~cm}^{-1}$ (0.2 molar ratio) before leveling-off to $\sigma \approx 40 \mathrm{~S} \mathrm{~cm}^{-1}$ for larger amounts of the acid dopant.

To obtain information about the doping efficiency of the TAG dopant, we determined the charge carrier concentration and charge carrier mobility for $\mathrm{P} 3 \mathrm{HT}$ and $\mathrm{p}\left(\mathrm{g}_{4} 2 \mathrm{~T}-\mathrm{T}\right)$ doped with EBSAc. We prepared polymer/EBSAc films with a varying molar ratio $(0.1,0.2,0.33$, and $0.66 \mathrm{EBSAc} /$ thiophene unit) and recorded the electrical conductivity after thermal activation of EBSAc. The films were then extensively washed with diethyl ether, and analysis of the extracted fractions by ${ }^{1} \mathrm{H}$ NMR allowed us to quantify the amount of EBSAc as well as the fraction of EBSA that can be removed from the film (Supporting Information Figure S9). We found that the efficiency of the decapping and of the doping was fundamentally different in P3HT and PTEG films. In P3HT, nearly all EBSAc was efficiently decapped upon activation, but a considerable amount of EBSA had not interacted with the polymer and hence could be removed. In PTEG, however, the EBSAc decapped only partially upon activation, but all decapped dopants appeared to be retained by the polymer (see Supporting Information Figure S10). Under the assumption that every retained EBSA molecule generates one charge on the polymer, we calculated the charge carrier concentrations in the range of $10^{20} \mathrm{~cm}^{-3}$ for both P3HT and PTEG. For doped P3HT, we calculated an average charge carrier mobility of $\mu \approx 4 \times 10^{-5} \mathrm{~cm}^{2} \mathrm{~V}^{-1} \mathrm{~s}^{-1}$ for all bound plus mobile charges, which increased by a factor of $\sim 2.5$ upon a 4 fold increase in the concentration of the EBSA dopant. In sharp contrast, we found that the charge carrier mobility of EBSA-doped $\mathrm{p}\left(\mathrm{g}_{4} 2 \mathrm{~T}-\mathrm{T}\right)$ increases by several orders of magnitude from $\mu \approx 8 \times 10^{-4} \mathrm{~cm}^{2} \mathrm{~V}^{-1} \mathrm{~s}^{-1}$ to $\mu \approx 2.6 \times$ $10^{-2} \mathrm{~cm}^{2} \mathrm{~V}^{-1} \mathrm{~s}^{-1}$ upon a 2 -fold increase in the concentration of the EBSA dopant.

We note that higher electrical conductivity values of aciddoped $\mathrm{p}\left(\mathrm{g}_{4} 2 \mathrm{~T}-\mathrm{T}\right)$ films are achieved over time and that processing in ambient atmosphere leads to higher electrical conductivities. As described by Mammone and MacDiarmid and shown in our recent work, ${ }^{52,60}$ acid doping yields higher electrical conductivities for samples prepared in air than for samples prepared under inert conditions, most likely because of the occurrence of an acid-mediated oxidation reaction. It was confirmed in this study that processing in air resulted in higher electrical conductivities of EBSA- and DBSA-doped P3HT, C16-PBTTT, and $\mathrm{p}\left(\mathrm{g}_{4} 2 \mathrm{~T}-\mathrm{T}\right)$ films, where the increase in electrical conductivity is more prominent for doping with pure acids and for the $\mathrm{p}\left(\mathrm{g}_{4} 2 \mathrm{~T}-\mathrm{T}\right)$ polymer (Supporting Information Figure S11a). To elucidate whether moisture in the air is a decisive factor in the doping step, we performed doping studies of $\mathrm{p}\left(\mathrm{g}_{4} 2 \mathrm{~T}-\mathrm{T}\right)$ with DBSA under ambient atmosphere, dry air, dry argon, and wet argon (Supporting Information Figure S11b). We find that the absence of water during our processing does not seem to reduce the electrical conductivity, whereas the absence of oxygen generally results in lower values for the electrical conductivity. Our results suggest that the (latent) acid-doping process in the case of $\mathrm{p}\left(\mathrm{g}_{4} 2 \mathrm{~T}-\mathrm{T}\right)$ does seem to involve a subsequent oxidation reaction.

We studied the environmental stability by exposing EBSAcdoped $\mathrm{p}\left(\mathrm{g}_{4} 2 \mathrm{~T}-\mathrm{T}\right)$ and P3HT films to ambient conditions for up to 2 weeks (Supporting Information Figure S12). After 1 day of aging in ambient atmosphere, EBSAc-doped P3HT samples achieved their highest electrical conductivity, whereas EBSAc-doped $\mathrm{p}\left(\mathrm{g}_{4} 2 \mathrm{~T}-\mathrm{T}\right)$ samples achieved their maximum electrical conductivity values after 2 days. Further aging showed a 1-2 orders of magnitude drop in the electrical conductivity for the doped P3HT samples within 1 day, whereas the electrical conductivity of doped $\mathrm{p}\left(\mathrm{g}_{4} 2 \mathrm{~T}-\mathrm{T}\right)$ was retained for 2 weeks and even increased for lower dopant concentrations. This result, combined with the already excellent long-term stability of acid-doped $\left.\mathrm{p}\left(\mathrm{g}_{4} 2 \mathrm{~T}-\mathrm{T}\right)\right)^{52}$ indicates that TAG doping has technological potential provided that a suitable polymer and TAG dopant combination is used.

TAG doping appears to be influenced by many factors, and optimization of activation conditions may further improve the electrical conductivity that can be achieved using the latent doping approach. Our results show that polythiophenes, such as P3HT, C16-PBTTT, and $\mathrm{p}\left(\mathrm{g}_{4} 2 \mathrm{~T}-\mathrm{T}\right)$, can be successfully doped with TAG dopants, which allows to increase the 
electrical conductivity of the polymers by 3-4 orders of magnitude upon thermal activation of the dopant.

Next, we explored solid-state processing of P3HT/EBSAc and P3HT/EBSA blends. The onset of the decapping temperature of the EBSAc molecule $\left(T_{\text {act,onset }} \approx 110{ }^{\circ} \mathrm{C}\right)$ lies well below the melting temperature of, for example, P3HT $\left(T_{\mathrm{m}}\right.$ $\left.\approx 248{ }^{\circ} \mathrm{C}\right)$ and $\operatorname{PBTTT}\left(T_{\mathrm{m}} \approx 244{ }^{\circ} \mathrm{C}\right)$, which prevents processing from the melt. However, previous work demonstrated that $\mathrm{P} 3 \mathrm{HT}$ could be processed at much lower temperatures into oriented films via hot-pressing at 100 ${ }^{\circ} \mathrm{C}$, ${ }^{61}$ allowing us to solid-state process P3HT/EBSAc blends without activation of the latent dopant. EBSA/P3HT and EBSAc/P3HT blends (0.66:1 molar ratio) were prepared by solution-mixing all components in $\mathrm{CHCl}_{3}$, followed by evaporation of the solvent (boiling point $=61{ }^{\circ} \mathrm{C}$ ). Then, each mixture as well as neat $\mathrm{P} 3 \mathrm{HT}$ reference material (sample size $\approx 20 \mathrm{mg}$ ) was solid-state-pressed at $70{ }^{\circ} \mathrm{C}$ for $30 \mathrm{~s}$ into disc-shaped samples (Figure 3a). Both pristine P3HT and the

\section{a}

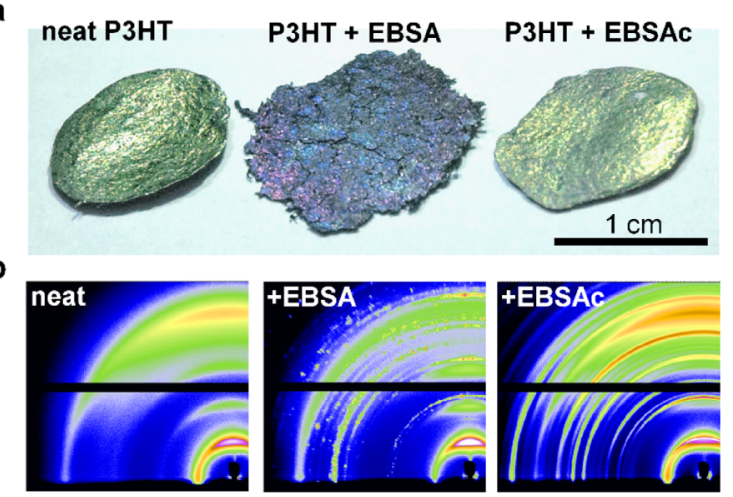

c
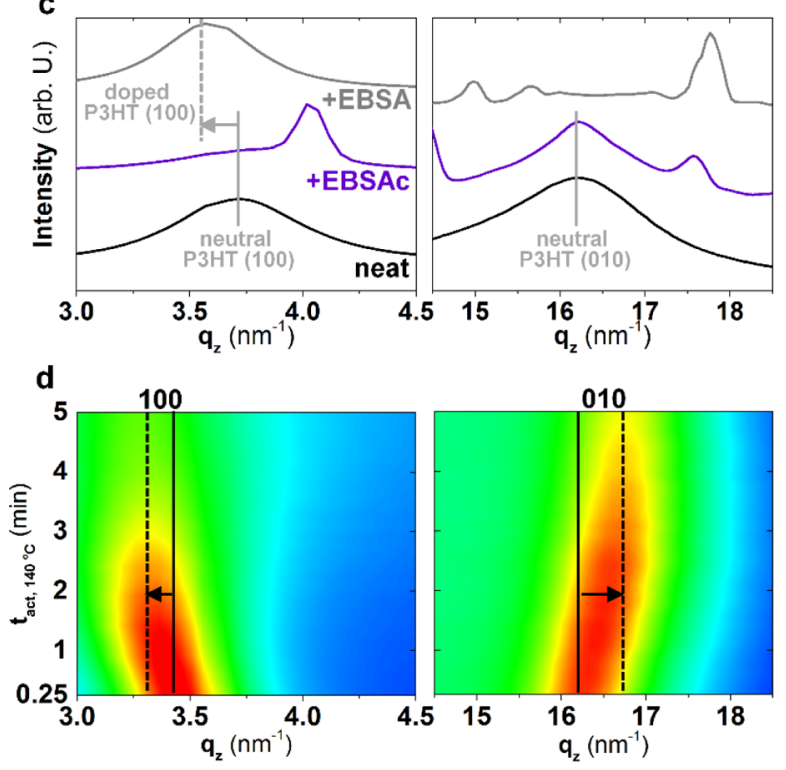

Figure 3. (a) Photograph of hot-pressed samples of P3HT, P3HT doped with EBSA, and P3HT processed with EBSAc; (b) WAXS images of the hot-pressed samples displayed in (a) measured at room temperature; (c) azimuthal plot of the (100) lamellar stacking diffraction (left) and the (010) $\pi$-stacking diffraction (right) of the samples in (a) at room temperature, integrated perpendicular to the films; and (d) diagram illustrating the time evolution of the (100) lamellar stacking diffraction (left) and the (010) $\pi$-stacking diffraction (right) of the P3HT/EBSAc sample during EBSAc activation at 140 ${ }^{\circ} \mathrm{C}$. WAXS was performed with the incedent X-ray parallel to the film.
P3HT/EBSAc blends were able to flow unrestrictedly, resulting in smooth, continuous films with a thickness of $\sim 130 \mu \mathrm{m}$. In contrast, EBSA-doped P3HT was considerably less malleable and inhomogeneous with numerous holes and cracks as a result of the intractable nature of doped P3HT.

We carried out wide-angle X-ray scattering (WAXS) to obtain more in-depth information regarding the solid-state nanostructure of each hot-pressed sample (Figure 3b,c). For hot-pressed samples of neat P3HT and P3HT/EBSAc, the appearance of both the lamellar and $\pi$-stacking diffraction $\left(d_{100}\right.$ $\left.\approx 1.6 \mathrm{~nm}, d_{010} \approx 0.39 \mathrm{~nm}\right)$ in the $q_{z}$-direction indicates that P3HT backbones within these samples are oriented horizontally to the plane of the films as a result of the shear they experienced during hot-pressing with a mixed "edge-on" and "face-on" texture. ${ }^{62}$ For pressed P3HT/EBSA, we find that the 100 diffraction peak is shifted, resulting in a slightly larger lamellar spacing of $d_{100} \approx 1.74 \mathrm{~nm}$, which we ascribe to incorporation of the dopant into the crystalline regions of P3HT. ${ }^{18,19,63}$ To further investigate the EBSAc decapping kinetics, we studied the microstructure evolution of P3HT/ EBSAc upon exposure to $140{ }^{\circ} \mathrm{C}$ by recording a diffraction spectrum every $15 \mathrm{~s}$ to construct a time-temperature plot displaying the evolution of the diffraction peaks in the $q_{z}$ direction during prolonged heating. We note that the initial diffraction peaks of all three samples measured at $140{ }^{\circ} \mathrm{C}\left(t_{\text {act }}=\right.$ $0.25 \mathrm{~min}$ ) are slightly shifted compared to the diffraction peaks of the same samples measured at room temperature. The lamellar spacing $\left(001, q_{\mathrm{z}} \approx 3.4 \mathrm{~nm}^{-1}\right.$ ) in the P3HT/EBSAc sample increased over time while the $\pi$-stacking distance $\left(010, q_{\mathrm{z}} \approx 16.2 \mathrm{~nm}^{-1}\right)$ decreased over a time span of $\sim 5 \mathrm{~min}$ (Figure 3d), after which no further change was observed, indicating that doping of P3HT was completed after 5 min. This change in lamellar and $\pi$-stacking distance was not observed in pristine $\mathrm{P} 3 \mathrm{HT}$ and $\mathrm{P} 3 \mathrm{HT} / \mathrm{EBSA}$ samples that were annealed at $140{ }^{\circ} \mathrm{C}$ (Supporting Information Figure S13).

As a final experiment, we performed dynamic mechanical analysis (DMA) to investigate the mechanical properties of $\sim 140 \mu \mathrm{m}$-thick neat P3HT and a P3HT/EBSAc film (EBSAc/ P3HT molar ratio $=1: 10$ ) before and after activation of the latent dopant (Figure 4).

With DMA, we performed a temperature sweep from -100 to $70{ }^{\circ} \mathrm{C}$ while following the evolution of the storage modulus, $E^{\prime}$, and the loss modulus, $E^{\prime \prime}$. For all samples, we observe a steady drop in the storage modulus, indicating that all three materials become less stiff with increasing temperature. For neat P3HT, $E^{\prime}$ is initially $\sim 2 \mathrm{GPa}$ at $-100{ }^{\circ} \mathrm{C}$, which drops slightly to about $1 \mathrm{GPa}$ at room temperature before decreasing relatively sharply to $\sim 100 \mathrm{MPa}$ at $70{ }^{\circ} \mathrm{C}$. At the same time, $E^{\prime \prime}$ reaches a maximum at $\sim 30{ }^{\circ} \mathrm{C}$, which marks the glasstransition temperature $\left(T_{\mathrm{g}}\right)$ of neat P3HT. The elastic modulus of the EBSAc/P3HT blend drops more rapidly to $\sim 330 \mathrm{MPa}$ at room temperature. We identify a $T_{\mathrm{g}} \approx 17^{\circ} \mathrm{C}$ and rationalize the reduction with regard to neat $\mathrm{P} 3 \mathrm{HT}$ with partial dissolution of EBSAc in the amorphous P3HT phase, allowing the TAG dopant to act as a plasticizer. From the DMA results, we also conclude that P3HT and the TAG dopant can be coprocessed without diminishing the mechanical integrity of the semiconductor polymer (cf. image of P3HT/EBSAc in Figure 3a). For the EBSAc/P3HT sample, we observe an additional peak at $\sim-33{ }^{\circ} \mathrm{C}$, which we tentatively attribute to the $T_{\mathrm{g}}$ of pure EBSAc (note that the WAXS data indicate that P3HT/EBSAc has partially phase-separated, cf. Figure 3c). Then, we subjected the P3HT/EBSAc sample to thermal 


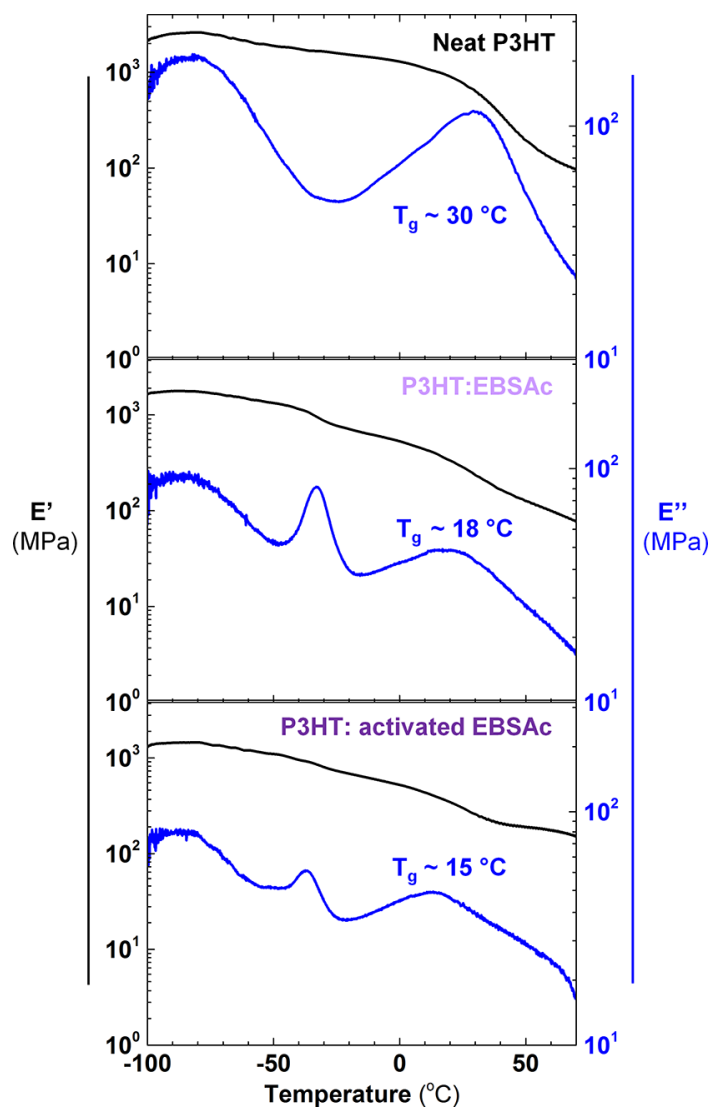

Figure 4. DMA storage and loss modulus ( $E^{\prime}$ and $\left.E^{\prime \prime}\right)$ of neat P3HT (top), P3HT/EBSAc (EBSAc/P3HT molar ratio $=1: 10$, or $\sim 16 \mathrm{wt}$ $\%)$ before activation (middle), and after activation by heating the sample at $140{ }^{\circ} \mathrm{C}$ for $5 \mathrm{~min}$ (bottom). The DMA test was performed with a dynamic strain of $0.02 \%$ at a frequency of $1 \mathrm{~Hz}$ with a heating rate of $3{ }^{\circ} \mathrm{C} \mathrm{min}^{-1}$ from -100 to $+70{ }^{\circ} \mathrm{C}$.

annealing for $5 \mathrm{~min}$ at $140{ }^{\circ} \mathrm{C}$ to activate the TAG dopant. The DMA curve of the activated EBSAc/P3HT sample shows a similar thermomechanical behavior as the pristine EBSAc/ P3HT sample. After thermal activation, the storage modulus at $70{ }^{\circ} \mathrm{C}$ of the doped P3HT sample, despite the presence of $\sim 2.2$ wt \% uncapped EBSAc and $\sim 1.6$ wt \% free EBSA and a trace of 2-nitrosobenzaldehyde (from an initial 16 wt \% EBSAc) (Supporting Information Figure S9a), is a factor of 2 higher than before activation of the dopant and 1.5 times higher than for pristine P3HT.

\section{CONCLUSIONS}

To summarize, we have shown that thermally activated dopant precursors can be coprocessed with various polythiophenes and that those can subsequently be doped in situ by thermal activation of the TAG dopant. In this way, we achieve the highest reported electrical conductivity $\left(\sim 22 \mathrm{~S} \mathrm{~cm}^{-1}\right)$ with regard to PAG/TAG dopant systems using the polar $\mathrm{p}\left(\mathrm{g}_{4} 2 \mathrm{~T}\right.$ T) and EBSAc combination that displays good stability under ambient conditions. Importantly, thermally activated doping allowed us to solid-state coprocess P3HT and EBSAc into 10's of $\mu \mathrm{m}$-thick structures, followed by doping by using heat as the external stimulus. From these results, we conclude that in situ doping with latent dopants offers an attractive avenue to considerably ease the preparation of doped bulk materials and offers a potential strategy for doping of embedded or encapsulated conjugated polymers.

\section{ASSOCIATED CONTENT}

\section{S Supporting Information}

The Supporting Information is available free of charge on the ACS Publications website at DOI: 10.1021/acs.chemmater.8b04895.

Synthetic procedures, ${ }^{1} \mathrm{H}$ NMR and ${ }^{13} \mathrm{C}$ NMR spectra, sample preparation, and additional characterization data including TGA and DSC thermograms, WAXS plots, UV-vis-NIR spectroscopy, and electrical measurements (PDF)

\section{AUTHOR INFORMATION}

\section{Corresponding Authors}

*E-mail: renee.kroon@chalmers.se (R.K.).

*E-mail: christian.muller@chalmers.se (C.M.).

ORCID

Renee Kroon: 0000-0001-8053-4288

Anna I. Hofmann: 0000-0002-4480-6028

Liyang Yu: 0000-0002-1203-2996

Christian Müller: 0000-0001-7859-7909

\section{Author Contributions}

${ }^{\dagger}$ R.K. and A.I.H. contributed equally to this work.

\section{Notes}

The authors declare no competing financial interest.

\section{ACKNOWLEDGMENTS}

We gratefully acknowledge the financial support from the Swedish Research Council through grant no. 2016-06146, the Knut and Alice Wallenberg Foundation through a Wallenberg Academy Fellowship, and the European Research Council (ERC) under grant agreement no. 637624. Prof. Martin Heeney and Dr. Zhuping Fei are kindly acknowledged for providing C16-PBTTT. The authors thank the Cornell High Energy Synchrotron Source (CHESS) (supported by the NSF \& NIH/NIGMS via NSF award DMR-1332208) for providing experimental time for GIWAXS measurements.

\section{REFERENCES}

(1) Lüssem, B.; Keum, C.-M.; Kasemann, D.; Naab, B.; Bao, Z.; Leo, K. Doped Organic Transistors. Chem. Rev. 2016, 116, 13714-13751.

(2) Lu, L.; Zheng, T.; Wu, Q.; Schneider, A. M.; Zhao, D.; Yu, L. Recent Advances in Bulk Heterojunction Polymer Solar Cells. Chem. Rev. 2015, 115, 12666-12731.

(3) Walzer, K.; Maennig, B.; Pfeiffer, M.; Leo, K. Highly Efficient Organic Devices Based on Electrically Doped Transport Layers. Chem. Rev. 2007, 107, 1233-1271.

(4) Russ, B.; Glaudell, A.; Urban, J. J.; Chabinyc, M. L.; Segalman, R. A. Organic thermoelectric materials for energy harvesting and temperature control. Nat. Rev. Mater. 2016, 1, 16050.

(5) Kroon, R.; Mengistie, D. A.; Kiefer, D.; Hynynen, J.; Ryan, J. D.; Yu, L.; Müller, C. Thermoelectric plastics: from design to synthesis, processing and structure-property relationships. Chem. Soc. Rev. 2016, $45,6147-6164$.

(6) Lund, A.; van der Velden, N. M.; Persson, N.-K.; Hamedi, M. M.; Müller, C. Electrically conducting fibres for e-textiles: An open playground for conjugated polymers and carbon nanomaterials. Mater. Sci. Eng., R 2018, 126, 1-29.

(7) Wei, W.; Peining, C.; Sisi, H.; Xuemei, S.; Huisheng, P. Smart Electronic Textiles. Angew. Chem., Int. Ed. 2016, 55, 6140-6169.

(8) Jin, H.; Matsuhisa, N.; Lee, S.; Abbas, M.; Yokota, T.; Someya, T. Enhancing the Performance of Stretchable Conductors for ETextiles by Controlled Ink Permeation. Adv. Mater. 2017, 29, 1605848 . 
(9) Taroni, P. J.; Santagiuliana, G.; Wan, K.; Calado, P.; Qiu, M.; Zhang, H.; Pugno, N. M.; Palma, M.; Stingelin-Stutzman, N.; Heeney, M.; Fenwick, O.; Baxendale, M.; Bilotti, E. Toward Stretchable SelfPowered Sensors Based on the Thermoelectric Response of PEDOT:PSS/Polyurethane Blends. Adv. Funct. Mater. 2018, 28, 1704285.

(10) Chen, D.; Pei, Q. Electronic Muscles and Skins: A Review of Soft Sensors and Actuators. Chem. Rev. 2017, 117, 11239-11268.

(11) Wang, S.; Oh, J. Y.; Xu, J.; Tran, H.; Bao, Z. Skin-Inspired Electronics: An Emerging Paradigm. Acc. Chem. Res. 2018, 51, 10331045.

(12) Jacobs, I. E.; Aasen, E. W.; Oliveira, J. L.; Fonseca, T. N.; Roehling, J. D.; Li, J.; Zhang, G.; Augustine, M. P.; Mascal, M.; Moulé, A. J. Comparison of solution-mixed and sequentially processed P3HT:F4TCNQ films: effect of doping-induced aggregation on film morphology. J. Mater. Chem. C 2016, 4, 3454-3466.

(13) Scholes, D. T.; Hawks, S. A.; Yee, P. Y.; Wu, H.; Lindemuth, J. R.; Tolbert, S. H.; Schwartz, B. J. Overcoming Film Quality Issues for Conjugated Polymers Doped with F4TCNQ by Solution Sequential Processing: Hall Effect, Structural, and Optical Measurements. J. Phys. Chem. Lett. 2015, 6, 4786-4793.

(14) Duong, D. T.; Phan, H.; Hanifi, D.; Jo, P. S.; Nguyen, T.-Q.; Salleo, A. Direct Observation of Doping Sites in TemperatureControlled, p-Doped P3HT Thin Films by Conducting Atomic Force Microscopy. Adv. Mater. 2014, 26, 6069-6073.

(15) Cao, Y.; Smith, P.; Heeger, A. J. Counter-ion induced processibility of conducting polyaniline and of conducting polyblends of polyaniline in bulk polymers. Synth. Met. 1992, 48, 91-97.

(16) Hamidi-Sakr, A.; Biniek, L.; Bantignies, J.-L.; Maurin, D.; Herrmann, L.; Leclerc, N.; Lévêque, P.; Vijayakumar, V.; Zimmermann, N.; Brinkmann, M. A Versatile Method to Fabricate Highly In-Plane Aligned Conducting Polymer Films with Anisotropic Charge Transport and Thermoelectric Properties: The Key Role of Alkyl Side Chain Layers on the Doping Mechanism. Adv. Funct. Mater. 2017, 27, 1700173.

(17) Patel, S. N.; Glaudell, A. M.; Kiefer, D.; Chabinyc, M. L. Increasing the Thermoelectric Power Factor of a Semiconducting Polymer by Doping from the Vapor Phase. ACS Macro Lett. 2016, 5, 268-272.

(18) Hynynen, J.; Kiefer, D.; Yu, L.; Kroon, R.; Munir, R.; Amassian, A.; Kemerink, M.; Müller, C. Enhanced Electrical Conductivity of Molecularly p-Doped Poly(3-hexylthiophene) through Understanding the Correlation with Solid-State Order. Macromolecules 2017, 50, $8140-8148$.

(19) Kang, K.; Watanabe, S.; Broch, K.; Sepe, A.; Brown, A.; Nasrallah, I.; Nikolka, M.; Fei, Z.; Heeney, M.; Matsumoto, D.; Marumoto, K.; Tanaka, H.; Kuroda, S.-i.; Sirringhaus, H. 2D coherent charge transport in highly ordered conducting polymers doped by solid state diffusion. Nat. Mater. 2016, 15, 896.

(20) Lim, E.; Peterson, K. A.; Su, G. M.; Chabinyc, M. L. Thermoelectric Properties of Poly(3-hexylthiophene) (P3HT) Doped with 2,3,5,6-Tetrafluoro-7,7,8,8-tetracyanoquinodimethane (F4TCNQ) by Vapor-Phase Infiltration. Chem. Mater. 2018, 30, 998-1010.

(21) Patel, S. N.; Glaudell, A. M.; Peterson, K. A.; Thomas, E. M.; O'Hara, K. A.; Lim, E.; Chabinyc, M. L., Morphology controls the thermoelectric power factor of a doped semiconducting polymer. Sci. Adv. 2017, 3. DOI: $10.1126 /$ sciadv. 1700434

(22) Kroon, R.; Ryan, J. D.; Kiefer, D.; Yu, L.; Hynynen, J.; Olsson, E.; Müller, C. Bulk Doping of Millimeter-Thick Conjugated Polymer Foams for Plastic Thermoelectrics. Adv. Funct. Mater. 2017, 27, 1704183.

(23) Zuniga, C. A.; Barlow, S.; Marder, S. R. Approaches to Solution-Processed Multilayer Organic Light-Emitting Diodes Based on Cross-Linking. Chem. Mater. 2011, 23, 658-681.

(24) Müller, C. D.; Falcou, A.; Reckefuss, N.; Rojahn, M.; Wiederhirn, V.; Rudati, P.; Frohne, H.; Nuyken, O.; Becker, H.; Meerholz, K. Multi-colour organic light-emitting displays by solution processing. Nature 2003, 421, 829.
(25) Jungermann, S.; Riegel, N.; Müller, D.; Meerholz, K.; Nuyken, O. Novel Photo-Cross-Linkable Hole-Transporting Polymers: Synthesis, Characterization, and Application in Organic Light Emitting Diodes. Macromolecules 2006, 39, 8911-8919.

(26) Rumer, J. W.; McCulloch, I. Organic photovoltaics: Crosslinking for optimal morphology and stability. Mater. Today 2015, 18, 425-435.

(27) Lee, C.-W.; Seo, Y.-H.; Lee, S.-H. A Soluble Polyaniline Substituted with t-BOC: Conducting Patterns and Doping. Macromolecules 2004, 37, 4070-4074.

(28) Lee, C.-W.; Kim, Y.-B.; Lee, S.-H. Synthesis and Properties of Tailor-Made Supramolecular Photo Acid Generators for Conducting Patterns of Polyaniline. Chem. Mater. 2005, 17, 366-372.

(29) Yang, K.; He, T.; Chen, X.; Cheng, S. Z. D.; Zhu, Y. Patternable Conjugated Polymers with Latent Hydrogen-Bonding on the Main Chain. Macromolecules 2014, 47, 8479-8486.

(30) Bouffard, J.; Watanabe, M.; Takaba, H.; Itami, K. Photopatterning of Poly(arylene dienylene) by the Photoacid-Catalyzed Deprotection-Elimination Reaction of a Precursor Polymer. Macromolecules 2010, 43, 1425-1429.

(31) Gather, M. C.; Köhnen, A.; Falcou, A.; Becker, H.; Meerholz, K. Solution-Processed Full-Color Polymer Organic Light-Emitting Diode Displays Fabricated by Direct Photolithography. Adv. Funct. Mater. 2007, 17, 191-200.

(32) Charas, A.; Alves, H.; Martinho, J. M. G.; Alcácer, L.; Fenwick, O.; Cacialli, F.; Morgado, J. Photoacid cross-linkable polyfluorenes for optoelectronics applications. Synth. Met. 2008, 158, 643-653.

(33) Yu, J.; Abley, M.; Yang, C.; Holdcroft, S. Chemically amplified photolithography of a conjugated polymer. Chem. Commun. 1998, $1503-1504$

(34) Park, M.-J.; Lee, J.-I.; Chu, H.-Y.; Kim, S.-H.; Zyung, T.; Eom, J.-H.; Shim, H.-K.; Hwang, D.-H. Light-emitting properties of photocurable polyfluorene derivatives. Synth. Met. 2009, 159, 1393-1397.

(35) Johnson, R. S.; Wheeler, D. R.; Dirk, S. M. Photolithographic patterning of alkoxy substituted poly(p-phenylenevinylene)s from xanthate precursors. J. Mater. Chem. C 2013, 1, 1428-1433.

(36) Renak, M. L.; Bazan, G. C.; Roitman, D. Poly(p-phenylene vinylene) copolymer patterns prepared via photolithographic techniques. Synth. Met. 1998, 97, 17-21.

(37) Potje-Kamloth, K.; Polk, B. J.; Josowicz, M.; Janata, J. Doping of Polyaniline in the Solid State with Photogenerated Triflic Acid. Chem. Mater. 2002, 14, 2782-2787.

(38) Salavagione, H. J.; Miras, M. C.; Barbero, C. Photolithographic Patterning of a Conductive Polymer Using a Polymeric Photoacid Generator and a Traceless Removable Group. Macromol. Rapid Commun. 2006, 27, 26-30.

(39) Venugopal, G.; Quan, X.; Johnson, G. E.; Houlihan, F. M.; Chin, E.; Nalamasu, O. Photoinduced Doping and Photolithography of Methyl-Substituted Polyaniline. Chem. Mater. 1995, 7, 271-276.

(40) Aoai, T.; Nishio, R.; Hayashi, N.; Nomura, K. Photo Doping Process of Conductive Polymer with PAG and Application for Organic Thermoelectric Materials. J. Photopolym. Sci. Technol. 2016, 29, 335-341.

(41) Lin, X.; Wegner, B.; Lee, K. M.; Fusella, M. A.; Zhang, F.; Moudgil, K.; Rand, B. P.; Barlow, S.; Marder, S. R.; Koch, N.; Kahn, A. Beating the thermodynamic limit with photo-activation of $\mathrm{n}$-doping in organic semiconductors. Nat. Mater. 2017, 16, 1209.

(42) Freudenberg, J.; Jänsch, D.; Hinkel, F.; Bunz, U. H. F. Immobilization Strategies for Organic Semiconducting Conjugated Polymers. Chem. Rev. 2018, 118, 5598-5689.

(43) Yu, J.; Holdcroft, S. Solid-State Thermolytic and Catalytic Reactions in Functionalized Regioregular Polythiophenes. Macromolecules 2000, 33, 5073-5079.

(44) Liu, J.; Kadnikova, E. N.; Liu, Y.; McGehee, M. D.; Fréchet, J. M. J. Polythiophene Containing Thermally Removable Solubilizing Groups Enhances the Interface and the Performance of PolymerTitania Hybrid Solar Cells. J. Am. Chem. Soc. 2004, 126, 9486-9487.

(45) Helgesen, M.; Gevorgyan, S. A.; Krebs, F. C.; Janssen, R. A. J. Substituted 2,1,3-Benzothiadiazole- And Thiophene-Based Polymers 
for Solar Cells - Introducing a New Thermocleavable Precursor. Chem. Mater. 2009, 21, 4669-4675.

(46) Amb, C. M.; Beaujuge, P. M.; Reynolds, J. R. Spray-Processable Blue-to-Highly Transmissive Switching Polymer Electrochromes via the Donor-Acceptor Approach. Adv. Mater. 2010, 22, 724-728.

(47) Abdulkarim, A.; Hinkel, F.; Jänsch, D.; Freudenberg, J.; Golling, F. E.; Müllen, K. A New Solution to an Old Problem: Synthesis of Unsubstituted Poly(para-phenylene). J. Am. Chem. Soc. 2016, 138, 16208-16211.

(48) Cameron, J. F.; Fréchet, J. M. J. Cationic curing of polymer coatings: Evaluation ofo-nitrobenzyl tosylate as a thermally labile acid precursor. Polym. Bull. 1991, 26, 297-303.

(49) Oberlander, J. E.; Wanat, S. F.; McKenzie, D. S.; Kokinda, E., Thermal acid generator (TAG) synthesis variables and their effect on resist performance, presented at Microlithography 2000, 2000.

(50) Angelopoulos, M.; Shaw, J. M.; Lee, K. L.; Huang, W. S.; Lecorre, M. A.; Tissier, M. Lithographic applications of conducting polymers. J. Vac. Sci. Technol., B: Microelectron. Nanometer Struct. 1991, 9, 3428-3431.

(51) Alveroglu, E. Doping effect of dodecyl benzene sulphonic acid in poly(3-hexylthiophene)-P3HT-films. J. Mol. Struct. 2015, 1086, $86-92$.

(52) Hofmann, A. I.; Kroon, R.; Yu, L.; Müller, C. Highly stable doping of a polar polythiophene through co-processing with sulfonic acids and bistriflimide. J. Mater. Chem. C 2018, 6, 6905-6910.

(53) Klán, P.; Šolomek, T.; Bochet, C. G.; Blanc, A.; Givens, R.; Rubina, M.; Popik, V.; Kostikov, A.; Wirz, J. Photoremovable Protecting Groups in Chemistry and Biology: Reaction Mechanisms and Efficacy. Chem. Rev. 2013, 113, 119-191.

(54) Houlihan, F. M.; Nalamasu, O.; Kometani, J. M.; Reichmanis, E. The Retrospective on 2-Nitrobenzyl Sulfonate Photoacid Generators. J. Imaging Sci. Technol. 1997, 41, 35-40.

(55) Barltrop, J. A.; Plant, P. J.; Schofield, P. Photosensitive protective groups. Chem. Commun. 1966, 822-823.

(56) Kroon, R.; Kiefer, D.; Stegerer, D.; Yu, L.; Sommer, M.; Müller, C. Polar Side Chains Enhance Processability, Electrical Conductivity, and Thermal Stability of a Molecularly p-Doped Polythiophene. Adv. Mater. 2017, 29, 1700930.

(57) Aktuna, S.; Alveroglu, E.; Koc, K. Camphor Sulfonic Acid Doped Poly(3-hexylthiophene) Nanofilms: Optical and Electrical Properties. J. Nanosci. Nanotechnol. 2017, 17, 467-473.

(58) Kao, C. Y.; Lee, B.; Wielunski, L. S.; Heeney, M.; McCulloch, I.; Garfunkel, E.; Feldman, L. C.; Podzorov, V. Doping of Conjugated Polythiophenes with Alkyl Silanes. Adv. Funct. Mater. 2009, 19, 19061911.

(59) Yuen, J. D.; Dhoot, A. S.; Namdas, E. B.; Coates, N. E.; Heeney, M.; McCulloch, I.; Moses, D.; Heeger, A. J. Electrochemical Doping in Electrolyte-Gated Polymer Transistors. J. Am. Chem. Soc. 2007, 129, 14367-14371.

(60) Mammone, R. J.; MacDiarmid, A. G. p-Doping of $(\mathrm{CH})$ to the metallic regime with gaseous oxygen. Application to oxygen fuel-celltype electrodes. J. Chem. Soc., Faraday Trans. 1 1985, 81, 105-112.

(61) Baklar, M. A.; Koch, F.; Kumar, A.; Domingo, E. B.; CampoyQuiles, M.; Feldman, K.; Yu, L.; Wobkenberg, P.; Ball, J.; Wilson, R. M.; McCulloch, I.; Kreouzis, T.; Heeney, M.; Anthopoulos, T.; Smith, P.; Stingelin, N. Solid-State Processing of Organic Semiconductors. Adv. Mater. 2010, 22, 3942-3947.

(62) Sirringhaus, H.; Brown, P. J.; Friend, R. H.; Nielsen, M. M.; Bechgaard, K.; Langeveld-Voss, B. M. W.; Spiering, A. J. H.; Janssen, R. A. J.; Meijer, E. W.; Herwig, P.; de Leeuw, D. M. Two-dimensional charge transport in self-organized, high-mobility conjugated polymers. Nature 1999, 401, 685.

(63) Duong, D. T.; Wang, C.; Antono, E.; Toney, M. F.; Salleo, A. The chemical and structural origin of efficient p-type doping in P3HT. Org. Electron. 2013, 14, 1330-1336. 